\title{
Select Nutrients in the Uterine Lumen of Sheep and Pigs Affect Conceptus Development
}

\author{
Fuller W. BAZER ${ }^{1,2)}$, Jinyoung KIM(2), Hakhyun KA ${ }^{3)}$, Gregory A. JOHNSON4), Guoyao WU1) \\ and Gwonhwa SONG ${ }^{2}$ \\ 1) Department of Animal Science and Center for Animal Biotechnology, Texas A\&M University, Texas 77843-2471, USA \\ ${ }^{2)}$ WCU Biomodulation Major, Department of Agricultural Biotechnology, Seoul National University, Seoul 151-921, Korea \\ ${ }^{3)}$ Division of Biological Science and Technology, IPAID and Institute of Biomaterials, Yonsei University, Wonju 220-710, \\ Korea \\ ${ }^{4)}$ Department of Veterinary Integrative Biosciences, Texas A\&M University, Texas 77843-4458, USA
}

\begin{abstract}
Interferon tau (IFNT) is the pregnancy recognition signal from ruminant conceptuses. IFNT also acts with P4 to induce expression of genes for transport of nutrients, such as glucose (Gluc) and arginine (Arg) into the uterine lumen to activate mechanistic mammalian target of rapamycin (MTOR) cell signaling that stimulates proliferation, migration, gene transcription and mRNA translation by conceptus trophectoderm (Tr). In ewes, Arg and Gluc increase significantly in the uterine lumen between Days 10 and 15 of pregnancy due to increased expression of transporters for Gluc (SLC2A1 and SLC5A1) and Arg (SLC7A2B) by uterine epithelia. Arg and Gluc stimulate proliferation, migration and mRNA translation by Tr. Arg increases expression of GTP cyclohydrolase 1 (GCHI) and IFNT mRNAs while Arg and Gluc increase ornithine decarboxylase, nitric oxide synthase 2, and GCH1 mRNAs and proteins by Tr cells. GCH1 is required for synthesis of tetrahydrobiopterin, an essential cofactor for all NOS isoforms. Arg is metabolized to nitric oxide and polyamines that increase proliferation and migration of Tr cells. In pigs, Gluc, Arg, leucine (Leu) and glutamine (Gln) increase in the uterine lumen between Days 12 and 15 of pregnancy due to enhanced expression of transporters for Gluc and amino acids. Transporters for Gluc in porcine uterine LE (SLC2A1) and conceptus trophectoderm (SLC2A2) are abundant. Transporters for glutamate and neutral (SLC1A1, SLC1A4) and cationic (SLC7A1, SLC7A2, SLC7A7, SLC7A9) amino acids are expressed in uterine LE and $S L C 7 A 3 \mathrm{mRNA}$ is expressed in conceptus Tr. Arg and Leu increase MTOR cell signaling and proliferation of pig Tr, as do Gluc and fructose. Azaserine, an inhibitor of hexosamine biosynthesis, inhibits effects of Gluc and fructose. Thus, select nutrients in the uterine lumen affect gene transcription and mRNA translation to affect conceptus development.
\end{abstract}

Key words: Amino acids, Fructose, Glucose, Uterus conceptus development

(J. Reprod. Dev. 58: 180-188, 2012)

E: stimates of embryonic death loss in mammals range from 20 to 40 percent and two-thirds of these losses occur during the peri-implantation period of pregnancy [1]. Establishment and maintenance of pregnancy requires appropriate development of the conceptus (embryo/fetus and its extra-embryonic membranes) for pregnancy recognition signaling to ensure maintenance of a functional corpus luteum (CL) to secrete progesterone (P4) that is required for an intrauterine environment that supports implantation, placentation and uterine functions essential for successful outcomes of pregnancy [2]. Interactions among the conceptus and uterine cell types, especially luminal (LE), superficial glandular (sGE) and glandular (GE) epithelia and stromal cells (SC), are essential for conceptus development, signaling for maternal recognition of pregnancy, uterine blood flow, water and electrolyte movement, transport of sugars and amino acids into the uterine lumen, as well as secretion of proteins by uterine epithelia and trophectoderm of

Received: November 1, 2011

Accepted: December 6, 2011

(C2012 by the Society for Reproduction and Development

Correspondence: FW Bazer (e-mail: fbazer@cvm.tamu.edu) the conceptus. Collectively, the components of uterine secretions and molecules transported into the uterine lumen are referred to as histotroph [3]. Individual conceptuses may fail to develop or not develop normally due to their failure to respond to components of histotroph that orchestrate their growth and development during the peri-implantation period of pregnancy. This review focuses primarily on select nutrients that are transported from maternal blood across the uterine epithelia and into the uterine lumen to affect conceptus development in sheep and pigs.

\section{Pregnancy Recognition Signaling}

Pregnancy recognition signaling mechanisms are variable among species and represent the natural evolution of strategies whereby the conceptus and maternal uterus communicate during the peri-implantation period and throughout pregnancy. Within the appropriate uterine environment, mammalian conceptuses signal pregnancy recognition to ensure maintenance of functional CL for production of $\mathrm{P} 4$. It is within the peri-implantation period that most embryonic deaths occur due to deficiencies attributed to uterine functions or to failure of the conceptus to develop appropriately, 
signal pregnancy recognition and/or undergo implantation and placentation.

\section{Pregnancy recognition in ewes}

Interferon tau (IFNT), the pregnancy recognition signal in ruminants, is secreted by mononuclear trophectoderm cells between Days 10 and 21 of pregnancy [4, 5]. IFNT suppresses transcription of estrogen receptor alpha (ESR1) and, therefore, estrogen-induced expression of the $O X T R$ gene in uterine LE/sGE to abrogate development of the uterine luteolytic mechanism requiring OXT-induced luteolytic pulses of prostaglandin $\mathrm{F}_{2 \alpha}$ (PGF). However, the uterus continues to secrete PGF to a greater extent in pregnant than cyclic ewes due to continued expression of prostaglandin synthase 2 (PTGS2). During the period of pregnancy recognition in ewes, P4 down-regulates expression of PGR in uterine epithelia between Days 12 to 13 after onset of estrus. Progesterone receptors (PGR) are not expressed during pregnancy which allows for expression of P4-induced and IFNT-stimulated genes in ovine uterine LE/sGE that are critical to conceptus growth and development.

\section{Pregnancy recognition in pigs}

Maternal recognition of pregnancy occurs on Days 11 to 12 in pigs. Pig conceptuses initially secrete estradiol-17 (E2) on Days 11 and 12 of pregnancy which activates mechanisms that redirect PGF secretion away from the uterine vasculature and into the uterine lumen. The theory of E2-induced maternal recognition of pregnancy in pigs is based on evidence that: (i) the uterine epithelia of nonpregnant gilts and sows secrete luteolytic PGF; (ii) pig conceptuses secrete E2 which is antiluteolytic; (iii) PGF is secreted into the uterine vasculature (endocrine) in cyclic gilts to induce luteolysis; and (iv) secretion of PGF in pregnant gilts is secreted into the uterine lumen (exocrine) where it is sequestered and metabolized to prevent its transport to CL to cause luteolysis [6]. In addition, PGE2 and lysophosphatidic acid (LPA) are important during pregnancy. Expression of PGE2 synthase by trophoblast and endometrium decreases production of PGF to favor PGE2 that supports CL maintenance. In addition, LPA increases in the uterine lumen of pigs, LPA receptors (LPAR3) are expressed by pig conceptuses and expression of LPAR3 increases in uterine epithelia in response to E2 during early pregnancy [7]. Further, LPA3 is essential for migration and spacing of pig blastocysts which is critical to implantation and placentation [8].

\section{The Uterine Lumenal Microenvironment Derives from the Secretome and Selective Transport of Nutrients}

A multitude of genes are expressed in a cell-specific and temporal manner by uterine LE, sGE, GE, SC, and resident immune cells that encode for secreted molecules and transporters of nutrients that create within the uterine lumen a complex mixture of molecules referred to as histotroph (Fig. 1). Histotroph includes proteins, ions, mitogens, cytokines, lymphokines, enzymes, hormones, growth factors, proteases and protease inhibitors, amino acids, glucose, fructose, vitamins and other substances. In the absence of uterine glands pregnancy fails early in the peri-implantation period of pregnancy in ewes [9] and embryonic mortality is increased and

\section{Uterine Microenvironment Secretome/Histotroph}

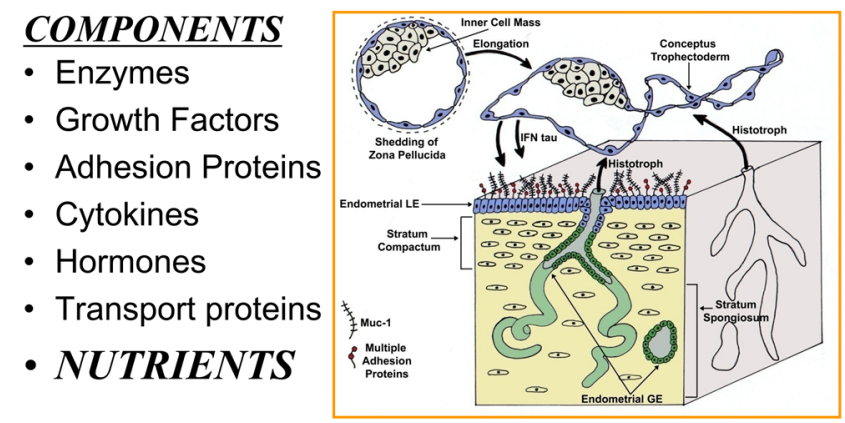

Fig. 1. The uterine microenvironment includes the secretome of uterine epithelia, as well as nutrients that are selectively transported into the uterine lumen to represent histotroph. Histotroph includes a variety of molecules that stimulate growth and development of the conceptus during the peri-implantation period and, indeed, for the duration of pregnancy in species with epitheliochorial and syndesmochorial placenta such as the pig and sheep, respectively.

litter size is decreased in pigs in which normal development of the uterine glands is compromised [10].

Of particular interest in this review are the roles of amino acids, glucose (Gluc) and fructose in supporting conceptus development in sheep and pigs. Mouse blastocysts are known to arrest in development when maintained for 5 days in culture medium lacking arginine (Arg), lysine and histidine [11], amino acids that cannot be synthesized by blastocysts. This result suggests that blastocyst expansion and implantation in vivo likely requires that these specific amino acids are present within the uterine lumen. Subsequently it was determined that mouse blastocysts require either leucine (Leu) or Arg in culture medium to exhibit expansion, motility and outgrowth of trophectoderm $[12,13]$. Both Leu and Arg initiate cell signaling via either serine-threonine kinase or mechanistic target of rapamycin (MTOR) cell signaling pathways to regulate protein synthesis and catabolism, and increase expression of mRNAs for insulin-like growth factor 2 (IGF2) [14], nitric oxide synthase (NOS) for synthesis of nitric oxide (NO) [12] and ornithine decarboxylase $(O D C 1)$ for synthesis of polyamines (putrescine, spermine and spermidine) [15]. Studies of mouse and human blastocysts revealed at least 14 amino acid transporters in the pregnant uterus, but the Leu-selective system $\mathrm{B}^{0,+}$ likely controls uptake of Leu and other amino acids that induce MTOR signaling critical to conceptus development [12]. This may allow the conceptus and uterus to coordinate differentiation of trophectoderm with development of uterine epithelia receptive to implantation. For example, Arg can be converted to ornithine by arginase and ornithine converted to putrescine, a polyamine, by ODC1 [16]. Polyamines stimulate proliferation and migration of trophectoderm cells and are required for the transition of mink blastocysts in delayed implantation to an activated state for expansion and implantation [17, 18]. Arg can also be metabolized by NOS to NO that stimulates proliferation 
and migration of ovine trophectoderm cells [19]. Arg may stimulate other cell signaling pathways, such as Rac activation [20], to stimulate cell proliferation and migration. Arg can also activate mitogen-activated protein kinase/extracellular-signal-regulated kinase (MEK/ERK) signaling, but the mechanism(s) whereby arginine activates MTOR complex 1 (MTORC1)/MTORC2 and/ or MEK/ERK is not known [21].

Unpublished results from our laboratory using an established pig trophectoderm cell line (pTr2) [22] indicate that select nutrients not only affect MTOR cell signaling, but a number of other key pathways affecting conceptus development (J. Kim and F.W. Bazer, unpublished results). First, Leu affects phosphorylation of $\beta$-catenin (also known as catenin (cadherin-associated protein), beta 1 ; CTNNB1) and cadherin in $\mathrm{pTr} 2$ cells and these proteins are involved in morula to blastocyst transition during embryonic development that is dependent on the formation of tight junction complexes $[23,24]$. Our preliminary results indicate that CTNNB1 phosphorylations at sties on adjacent cell membranes in response to Leu is inhibited dependent on PI3K (i.e., it is inhibited by LY294002), but not MTOR (i.e., it is not inhibited by rapamycin). Formation of tight junctions and adherens junctions including binding of the catenin-cadherin complex to actin cytoskeleton is necessary for polarization of blastomeres in morula stage embryos and is a prerequisite for formation of the blastocyst [25]. The polarized trophectoderm can engage in active transport of water and select nutrients into the blastocoel $[26,27]$.

Select nutrients also appear to effect changes in the organization of actin filaments in pTr2 cells (J. Kim and F.W. Bazer, unpublished results). The actin filaments of pTr2 cells in medium without Arg or Leu are closely grouped and parallel to the lateral cell wall whereas the actin filaments assume a basket-like arrangement with equidistant spacing along the entire surface of the $\mathrm{pTr} 2$ cells in the presence of Arg or Leu. The change in orientation of the actin filaments may contribute to changes in shape of pig blastocysts as they transition from spherical to tubular and filamentous forms. Published results indicate that pig trophectoderm cells in the elongation zone are columnar compared to cuboidal in areas peripheral to the elongation zone and this structural modification is associated with changes in length and orientation of microfilaments as early as in $10 \mathrm{~mm}$ diameter blastocysts [28, 29]. Within the elongation zone, alterations in microfilaments and junctional complexes of pig trophectoderm cells and extension of filopodia from extra-embryonic endodermal cells allow movement and redistribution of cells toward the ends of tubular blastocysts. The actin cytoskeleton in pig trophectoderm cells during the transition from spherical to tubular and filamentous forms initially exhibits a pericellular distribution that later forms continuous actin-rich lateral borders and stress fibers along their basal surface [30, 31]. The actin cytoskeleton, in association with myosin II, is essential for force generation for conceptus elongation as constricted regions along the length of filamentous conceptuses contain polarized trophectoderm cells with a distinct F-actin array. This mechanism for elongation of pig conceptuses is likely similar for conceptuses of sheep and other livestock species in which elongation occurs due to a reduction in diameter and a rapid increase in length of trophectoderm.
Phosphorylation of serine 10 in the tail of histone $\mathrm{H} 3$ is involved in both transcription and mitosis, requiring opposite alterations in chromatin condensation. Histone $\mathrm{H} 3$ phosphorylation at serine10 by ribosomal protein S6 kinase (90 kd RPS6KA or RSK) is linked to transcriptional activation of mitogen-stimulated immediate-early response genes, such as c-fos and c-jun and other inducible genes and oncogenes [32]. In addition, histone $\mathrm{H} 3$ phosphorylation at serine10 is colocalized with phosphorylated MTOR and ribosomal protein S6 kinase (70 kd RPS6K) associated with the mitotic spindle and mitosis in highly proliferative cells [33]. Cross-talk resulting from phosphorylation of histone $\mathrm{H} 3$ at serine 10 can enhance acetylation of histone $\mathrm{H} 3$ at lysine 14, abolish acetylation of histone $\mathrm{H} 3$ at lysine 9 and inhibit methylation of histone $\mathrm{H} 3$ at lysine 9. Using the pTr2 cell line, Arg and Leu stimulated phosphorylation of histone $\mathrm{H} 3$ at serine 10 and this effect was also induced to a lesser extent when pTr2 cells were treated with glutamine (Gln) and Gluc (J. Kim and F.W. Bazer, unpublished results). These results indicate that select nutrients also stimulate transcription of genes critical to growth and development of trophoblast cells. Further, these results suggest that MTOR/S6K1 and MAPK/RSK signaling pathways coordinately regulate conceptus and trophoblast development by influencing uptake of nutrients.

\section{The ewe}

The primary roles of IFNT are to: 1) abrogate development of the uterine luteolytic mechanism to ensure maintenance of ovarian CL to produce P4; and 2) silence expression of ESR1 to ensure that PGR are not up-regulated in uterine epithelia which allows for expression of many genes [3-5]. Another key role of IFNT is induction of expression of interferon regulatory factor 2 (IRF2) in uterine LE/sGE to directly silence expression of classical interferon stimulated genes, including signal transducer and activator of transcription (STAT1 and STAT2) and IRF9 by those cells. In the absence of PGR and STAT1 in uterine LE/sGE, P4 induces and IFNT further stimulates expression of a growing number of genes by uterine LE/sGE that are in direct contact with conceptus trophectoderm and are critical to development of the conceptus. However, IFNT also induces expression of classical interferon stimulated genes in uterine GE and stromal cells that may be important in pregnancy.

A paradox is that cessation of expression of PGR and ESR 1 by uterine epithelia is a prerequisite for uterine receptivity to implantation and for expression of genes induced by P4 alone, IFNT alone or induced by $\mathrm{P} 4$ and further stimulated by IFNT in uterine LE/ sGE, GE and SC (see Table 1). Down-regulation of PGR in ovine uterine LE is correlated with loss of MUC1 (mucin 1, cell surface associated) which is a prerequisite for attachment of conceptus trophectoderm to uterine LE for implantation [34]. Silencing expression of $P G R$ in uterine epithelia is preceded by $\mathrm{P} 4$ actions via PGR-positive uterine $\mathrm{SC}$ to induce expression of one or more progestamedins, e.g., fibroblast growth factor-7 (FGF7), FGF10 and/or hepatocyte growth factor (HGF). These growth factors exert paracrine effects on uterine LE/sGE, GE and conceptus trophectoderm that express receptors for FGF7 and FGF10 (FGFR2IIIb) and HGF (MET; protooncogene MET) in ewes, but FGF10 is the primary progestamedin expressed by uterine SC [35-37]. 
Table 1. Genes expressed by ovine uterine luminal (LE), superficial glandular (sGE) and glandular (GE) epithelia in response to progesterone (P4) and/ or interferon tau (IFNT) and placental lactogen (CSH1) [2-4]

\begin{tabular}{|c|c|c|c|}
\hline Gene & $\begin{array}{l}\text { Cell-specific } \\
\text { expression }\end{array}$ & $\begin{array}{l}\text { Regulation of } \\
\text { expression }\end{array}$ & Function \\
\hline $\begin{array}{l}\text { WNT7A, Wingless-Type MMTV Integration Site Family, } \\
\text { Member 7A }\end{array}$ & $\mathrm{LE} / \mathrm{sGE}$ & IFNT & Morphogen \\
\hline GRP, Gastrin Releasing Peptide & $\mathrm{LE} / \mathrm{sGE} / \mathrm{GE}$ & P4/IFNT & Morphogen \\
\hline IRF6, Interferon Regulatory Factor 6 & $\mathrm{LE} / \mathrm{sGE} / \mathrm{GE}$ & P4/IFNT & Cell Proliferation/ Differentiation \\
\hline CST3, Cystatin C & $\mathrm{LE} / \mathrm{sGE}$ & P4/IFNT & Protease Inhibitor \\
\hline CSTL, Cathepsin L & $\mathrm{LE} / \mathrm{sGE}$ & P4/IFNT & Protease \\
\hline SPP1, Secreted Phosphoprotein 1 & GE & $\mathrm{P} 4 / \mathrm{CSH} 1$ & Implantation/Placentation \\
\hline LGALS15, Galectin 15 & LE/sGE & P4/IFNT & Cell Migration and Adhesion \\
\hline POSTN, Periostin & $\mathrm{LE} / \mathrm{sGE}$ & P4 & Cell Adhesion \\
\hline IGFBP1, Insulin-Like Growth Factor Binding Protein 1 & $\mathrm{LE} / \mathrm{sGE}$ & P4/IFNT & Cell Migration and Adhesion \\
\hline enJSRV, Endogenous Jaksekete Retrovirus & $\mathrm{LE} / \mathrm{GE}$ & P4 & Morphogen, Cell Differentiation, Antiviral System \\
\hline HGF, Hepatocyte Growth Factor & $\mathrm{SC}$ & $\mathrm{P} 4$ & Stromal-Epithelial Cell Signaling \\
\hline FGF10, Fibroblast Growth Factor 10 & $\mathrm{SC}$ & P4 & Stromal-Epithelial Cell Signaling \\
\hline MET, Oncogene MET & $\mathrm{LE} / \mathrm{sGE}$ & $\mathrm{P} 4$ & Hepatocyte Growth Factor Receptor \\
\hline HIF1A, Hypoxia-Inducible Factor & $\mathrm{LE} / \mathrm{sGE}$ & P4/IFNT & Erythropoiesis, Angiogensis, Glycolysis \\
\hline STC1, Stanniocalcin 1 & GE & $\mathrm{P} 4 / \mathrm{CSH} 1$ & Calcium Binding \\
\hline HSD11B1, Hydroxysteroid Dehydrogenase-11 Beta 1 & $\mathrm{LE} / \mathrm{sGE}$ & P4/IFNT & Converts Corticosterone to Cortisol \\
\hline PTGS2, Prostaglandin Synthase 2 & LE/sGE & P4/IFNT & Synthesis of Prostaglandins \\
\hline GCCR, Glucocorticoid Receptor & $\mathrm{LE} / \mathrm{sGE}$ & P4/IFNT & Glucocortoid Receptor \\
\hline IRF2 & $\mathrm{LE} / \mathrm{sGE}$ & P4/IFNT & Transcriptional Repressor \\
\hline GLYCAM1, Glycosylation Dependent Cell Adhesion Molecule 1 & $\mathrm{LE} / \mathrm{sGE}$ & P4 & Ligand for Leukocyte Cell Surface Selectin \\
\hline MUC1, Mucin 1 & LE & P4 & Inhibits Cell-Cell and Cell-ECM Interactions \\
\hline PRLR, Prolactin Receptor & GE & P4 & Prolactin Receptor/Mitogenesis/Gene Expression \\
\hline SERPIN, Serine Protease Inhibitor & GE/CSH1 & $\mathrm{P} 4$ & Serine Protease Inhibitor \\
\hline
\end{tabular}

Genes induced by $\mathrm{P} 4$ and further stimulated by IFNT in ovine uterine LE/sGE lacking $P G R$ and STATI and in direct contact with conceptus trophectoderm during the peri-implantation of pregnancy include [3-5]: 1) morphogens (gastrin releasing peptide, GRP and $I R F 6$ ); 2) proteases (cathepsin L, CSTL); 3) protease inhibitors (cystatin C, CST3); 4) mediators of cell migration and adhesion including galectin 15 (LGALS15), periostin (POSTN) and insulin-like growth factor binding protein 1 (IGFBP1); 5) hypoxia inducible factors (HIF1A and $H I F 2 A$ ) that stimulate angiogenesis and erythropoiesis; 6) hydroxysteroid dehydrogenase $11 \mathrm{~B}(H S D 11 B 1)$ that mediates corticosterone metabolism and expression of glucocorticoid recetors $(G C C R) ; 7)$ synthesis of prostaglandins (prostaglandin synthase 2 , PTGS2) [46]; and 8) IRF2 a potent repressor of transcription [35]. In addition, P4 induces and IFNT further stimulates a number of genes required for transport of Gluc (solute carrier family 2 (facilitated Gluc transporter), member 1, SLC2A1; SLC5A11) and cationic amino acids such as Arg (solute carrier family 7 (cationic amino acid transporter, y+ system), member 2, SLC7A2).

Conceptus growth and development requires amino acids, Gluc, fatty acids, vitamins and minerals. Before placentation, these nutrients are transported from maternal plasma into the uterine lumen. Thereafter, they are supplied to the fetus through the umbilical circulation. Both amino acids and Gluc are major sources of energy for the embryo/fetus and amino acids are building blocks of proteins and some amino acids (e.g., branched-chain amino acids, glutamate, serine, and proline) undergo extensive catabolism in the placenta [16]. Gln is the most abundant amino acid in fetal plasma and is present at exceedingly high concentrations in fetal fluids (2-20 mM depending on Day of gestation) [16]. Interestingly, the placentae of sheep, pigs and rats have a limited ability to degrade Gln due to the lack of glutaminase and use Arg in a species-dependent manner. For example, the ovine placentome actively degrades Arg by arginase, but the porcine placenta lacks this pathway [16]. Notably, the ovine conceptus uses citrulline as an effective precursor of Arg to support fetal growth [38, 39].

The MTOR cell signaling pathway is an evolutionarily conserved serine/threonine kinase located downstream of PI3K that is central to control of cell growth and proliferation through regulation of mRNA translation for protein synthesis and cell proliferation [40]. Cellular events directly controlled by the MTOR pathway include mRNA translation, ribosome synthesis, expression of metabolismrelated genes, autophagy and cytoskeletal reorganization [41]. During embryonic development, molecules that stimulate MTOR activity may also stimulate translation of mRNAs critical to blastocyst/conceptus development, including insulin-like growth factor 2 (IGF2) and actions of selected amino acids as MTOR is a "nutrient sensing system" [12]. Cell signaling via MTOR stimulates cell migration and invasion, as well as cell growth and proliferation in different cell types [42]. In fact, $m$ TOR/Frapl null mice die shortly after implantation due to impaired cell proliferation and hypertrophy 
in both the embryonic disc and trophoblast [43].

Nutrients are essential components of histotroph required for development and survival of conceptuses during pregnancy [16, 44]. Results from a systematic study of temporal and cell-specific changes in expression of transporters for Gluc and amino acids, their regulation by $\mathrm{P} 4$ and/or IFNT, changes in expression of NOS isoforms, ODC and related proteins, as well as components of MTORC1 and MTORC2 cell signaling in ovine uteri and conceptuses have been reported [45-50]. The results indicate that: 1) total recoverable Gluc, Arg, Leu, Gln, glutathione, calcium and sodium are more abundant in the uterine lumen of pregnant than cyclic ewes between Days 10 and 16 after onset of estrus or mating; 2) uteri and conceptuses express tissue and cell-specific facilitative and sodium-dependent transporters for Gluc, as well as for cationic, acidic and neutral amino acids, some of which are regulated by $\mathrm{P} 4$ or $\mathrm{P} 4$ and IFNT; 3) transport of Arg into the uterine lumen and uptake by conceptuses is by System y+ (SLC7A1, A2, and A3) cationic amino acid transporters; 4) NOS1 and ODC1 are most abundant in uterine LE/sGE while NOS3 is most abundant in trophectoderm and endoderm of conceptuses; 5) expression of GCH1, the key enzyme for synthesis of tetrahydrobiopterin, a cofactor for NO production by all NOS isoforms, as well as ODC1 and NOS1 are more abundant in conceptuses than uterine cells; and 6) P4 stimulates expression of NOS1 and GCH1, while IFNT inhibits expression of NOS1. Further, components of both the MTORC1 and MTORC2 cell signaling pathways (FKBP12-rapamycin complexassociated protein 1,FRAP1; MTOR-associated protein LST8, LST8; mitogen-activated protein kinase-associated protein 1, MAPKAP1; regulatory associated protein of MTOR, RAPTOR; rapamycin insensitive companion of MTOR, RICTOR; tuberous sclerosis 1, TSC1; TSC2; ras homolog enriched in brain, RHEB; and eukaryotic initiation factor $4 \mathrm{E}$ binding protein, EIF4EBP1) are localized to uterine LE/sGE, GE and SC, as well as trophectoderm and endoderm of conceptuses between Days 13 and 18 of pregnancy. The abundance of FRAP1, RAPTOR, RICTOR, TSC1 and TSC2 mRNAs in the uterine endometrium was not affected by pregnancy status, day of the estrous cycle or day of pregnancy. However, expression of $L S T 8, M A P K A P 1, R H E B$ and $E I F 4 E B P 1 \mathrm{mRNAs}$ increased only in the endometrium during early pregnancy. Further, P4 and IFNT stimulated expression of RHEB and EIF4EBP1 in uterine endometria. Importantly, FRAP1 was abundant in cytoplasm and phosphorylated FRAP1 was very abundant in nuclei of ovine trophectoderm cells and endoderm, and increases in abundance of RICTOR, RHEB and EIF4EBP1, and RHEB protein in endometria were coordinate with rapid conceptus growth and development during the peri-implantation period. These results suggest differential effects of MTORC1 and MTORC2 on elongation of ovine conceptuses.

Results of recent in vitro studies $[19,51]$ with an established ovine trophectoderm cell line (oTr) indicated novel cell signaling whereby: 1) Arg activates MTOR cell signaling and phosphorylation of ribosomal protein s6 kinase, 70kd, 2 (RPS6KB); Arg, Leu and Gluc increase phosphorylation of V-AKT murine thymoma viral oncogene homolog 1 (AKT1), glycogen synthase kinase 3B (GSK3B), FRAP1 and RPS6KA2 proteins; 3) Arg increases the abundance of phosphorylated RPS6KB (pRPS6KB) and pRPS6 in

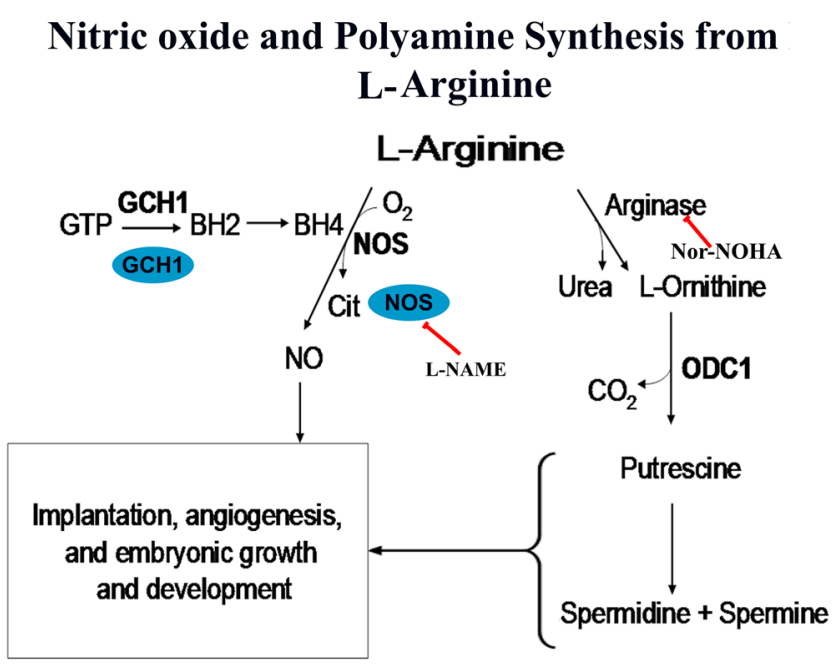

Fig. 2. L-Arginine can affect proliferation and migration of ovine trophectoderm cells by being converted to nitric oxide (NO) by nitric oxide synthase (NOS) or by being converted to Lornithine by arginase with ornithine then being converted to polyamines by ornithine decarboxylase. Inhibition of NOS with L-NAME [N5-imino(nitroamino)methyl-L-ornithine, methyl ester, monohydrochloride] and arginase with Nor-NOHA [2Samino-4- (hydroxyamino) iminomethyl amino-butanoic acid, dihydrochloride, hydrate] decreases the stimulatory effects of L-arginine on proliferation and migration of ovine trophectoderm cells.

the cytoplasm of oTr cells; and 4) Arg stimulation of proliferation of oTr cells is inhibited by inhibitors of production of both NO and polyamines (Fig. 2).

Kim et al. [52] used Day 16 ovine conceptuses for explants cultures to determined effects of Arg, Leu, Gln and Gluc on gene expression and protein synthesis. Expression of MTOR, RPS6K, RPS6 and $4 E B P 1$ mRNAs were not affected by treatment with any of the select nutrients. Similarly, expression of IFNT, NOS2, NOS3 and $O D C 1$ mRNAs were not different except for $G C H 1$ mRNA which increased in response to Arg. Importantly, Arg, Leu, Gln and Gluc increased the abundance of pMTOR, pRPS6K, pRPS6 and p4EBP1 proteins, as well as NOS and ODC1 proteins, but only Arg increased the abundance of IFNT protein. These findings indicate that the select nutrients tested stimulate translation of mRNAs to increase synthesis of proteins through phosphorylation and activation of components of the MTOR signaling pathway. An increase in abundance of IFNT protein, the pregnancy recognition signal, NOS2, NOS3 and GCH1 for conversion of Arg to NO, and ODC1 for synthesis of polyamines are all important for growth and development of the ovine conceptus during pregnancy.

An ovine model of early administration of exogenous $\mathrm{P} 4$ at $36 \mathrm{~h}$ after onset of estrus, i.e., about $6 \mathrm{~h}$ post-ovulation, has been used to advance conceptus development and IFNT secretion in ewes. Using this model, early P4 accelerated conceptus development was associated with advanced expression of uterine genes essential for events of early pregnancy that favor survival, growth and development of the conceptus [37, 53-55]. An early increase in circulating concentrations of P4: 1) advanced the time of down-regulation of 
PGR in uterine epithelia and onset of secretion and abundance of IFNT in uterine flushings; 2) increased abundance of LGALS15, CTSL, GRP, stanniocalcin 1 (STC1), and IGFBP1 by uterine LE/ sGE [37, 53, 56-59]; 3) increased expression of FGF10 and MET mRNA, suggesting that FGF10 is the primary uterine stromal cell-derived progestamedin stimulated by P4 [37]; 4) increased MET mRNA to increase responsiveness of uterine LE/sGE to HGF and enhance conceptus development as FGFR2IIIb and MET are expressed by both uterine epithelia and trophectoderm [35-37]; 5) transiently decreased tight-junction associated proteins in uterine LE that may facilitate paracellular trafficking and/or transport of stromal and serum-derived molecules [54]; 6) increased total recoverable Gluc, aspartic acid, asparagine, serine, alanine, Gln, beta-alanine, citrulline, Arg, and lysine in the uterine lumen on Day 9 [55]; 7) increased steady-state levels of SLC2A1 and SLC5A1 mRNAs and proteins in uterine LE/sGE for glucose transport; and 8) increased steady-state levels of SLC7A2 mRNA in uterine LE/ sGE for transport of cationic amino acids, particularly Arg [55].

NO is a key regulator of angiogenesis during pregnancy that is derived from NOS3 and/or NOS2 expressed by placentae of rodents, humans, pigs, and sheep. Polyamines and NO are essential to placental growth and angiogenesis as rats fed Arg-free diets experience reduced NO synthesis, increased fetal resorptions, intrauterine growth retardation (IUGR), increased perinatal mortality and decreased numbers of live pups at birth [16]. Also, oral administration of Arg ( $3 \mathrm{~g}$ daily for 4 weeks) to women with preeclampsia increased NO synthesis which was associated with reduced blood pressure, prolonged pregnancy, improved fetal well-being, enhanced fetal growth and uterine quiescence to prevent preterm labor [16]. In ewes, placental synthesis of NO and polyamines is essential for placental angiogenesis and growth that increase markedly between Days 30 and 60 of gestation when placental growth and placentomal development are most rapid [60]. Inhibition of NOS or ODC1 activity during early pregnancy markedly reduces placental size that leads to IUGR in rats. Increases in NO synthesis in sheep placentomes from Day 100 of gestation are coordinate with significant increases in placental-fetal blood flow and rapid fetal growth. In ovine placentae and endometria, both NADPH and BH4 increase markedly between Days 40 and 60 of gestation along with increases in concentrations of citrulline (the precursor of Arg) and Arg in allantoic fluid. Between Days 80 and 100 of gestation, $\mathrm{BH} 4$ concentrations also increase in placentomes and endometria, as do concentrations of Arg in allantoic fluid. Arg is a potential regulator of the pentose cycle activity and a stimulator of endothelial GCH1 expression critical for regulating the synthesis of $\mathrm{NADPH}$ and $\mathrm{BH} 4$ and $\mathrm{NO}$ production in placenta and endometrium which prevents or ameliorates intrauterine growth retardation and development of hypertension and pre-eclampsia [16].

\section{The pig}

Pig conceptuses secrete E2 between Days 10 and 15 for pregnancy recognition, but also to increase expression of genes by uterine LE that act on conceptus trophectoderm to stimulate proliferation, migration, adhesion and gene expression that supports implantation and development of the conceptus. The increase in secretion of E2 between Days 15 and 30 of pregnancy also increases expression of endometrial receptors for PRL, uterine secretory activity and uterine blood flow. The limited number of E2-stimulated genes that have been localized in endometria of pigs include: aldo-keto reductase family 1 , member $\mathrm{B} 1(A K R 1 B 1)$, beta 2 microglobulin $(B 2 M), \mathrm{CD} 24$ antigen (CD24), lysophophatidic acid receptor (LPAR3), $F G F 7$ 7 IRF2, myxovirus resistance 1, mouse, homolog of $(M X 1)$, neuromedin B $(N M B)$, swine leukocyte antigens (SLAs 1, 2, 3, 6, 7, 8), SLC5A1, SLC2A1 and SLC2A4, SPP1 and STC1 [61]. IGF1 is expressed by uterine glands of cyclic and pregnant pigs and IGF1 receptors are expressed by cells of the endometrium and conceptuses, suggesting paracrine and autocrine effects of IGFI. Although FGF7 is a unique SC-derived paracrine mediator of hormone-regulated epithelial growth and differentiation, the uterine luminal epithelium of the pig is unique in its expression of FGF7 in response to E2 with P4 being permissive to effects of E2 [62]. FGF7 binds to and activates FGFR2IIIb expressed by uterine epithelia and conceptus trophectoderm to increase cell proliferation, phosphorylated FGFR2IIIb, the MAPK cascade and expression of urokinase-typeplasminogen activator (PLAU), a marker for trophectoderm cell differentiation.

From about Day 20 of pregnancy, FGF7 is expressed by uterine $\mathrm{GE}$ in response to $\mathrm{P} 4$ and is presumed to continue to affect uterine epithelia and conceptus development in pigs [63, 64]. Indeed, P4 has profound effects on the expression of genes in pig uterine epithelia, particularly in the GE. Long-term administration of P4 to ovariectomized gilts supports initial gene regulatory events that occur during the late luteal phase and the peri-implantation period of intact cyclic and pregnant pigs including down-regulation of PGR in uterine LE and GE, and induction of acid phosphatase 5, tartrate resistant (ACP5, commonly referred to as uteroferrin) in GE, but disregulates some delayed gene expression that occurs after Day 30 of pregnancy including induction of SPP1 in GE. Notably, $F G F 7$ has a similar pattern of GE expression to SPP1 during pig pregnancy, but diverges from SPP1 in its endocrine regulation in that it is induced in GE by long-term progesterone whereas SPP1 is not increased in GE by P4 alone. Collectively, these results suggest that the hormonal milieu necessary for the production of histotroph from GE varies for its individual components, and that genes that delay expression in GE until after the peri-implantation period may require specific servomechanisms of sequential exposure of the pregnant endometrium to ovarian, conceptus/placental and/ or uterine factors that may include progesterone, estrogens, IFNs and prolactin $[64,65]$.

Glucose present in the intrauterine environment of pigs and sheep can be metabolized, activate cell signaling pathways or be converted to a "storage" form. Total recoverable Gluc in uterine fluid of pregnant, but not cyclic pigs increases from Day 12 after onset of estrus in concert with conceptus elongation [63]. Studies of sexually mature gilts to identify effects of pregnancy, long-term treatment of ovariectomized gilts with P4 and E2-induced pseudopregnancy on changes in amounts of select nutrients (Gluc, Arg, Leu and Gln) in uterine fluid and expression of Gluc transporters in endometria and conceptuses were conducted [G.A. Johnson and F.W. Bazer, unpublished results]. In comparing effects of day of the estrous cycle and pregnancy on total recoverable Gluc, Arg, Leu and Gln in uterine flushings from gilts on Days 5, 9, 12 and 15 of 
the estrous cycle and Days 9, 10, 12, 13, 14 and 15 of pregnancy, we found that total recoverable Gluc, Arg, Leu and Gln increased $(\mathrm{P}<0.05)$ with day in both cyclic and pregnant gilts, but only Arg increased more in pregnant than cyclic gilts between Days 12 and 15. Results from the study of gilts ovariectomized on Day 12 and treated daily with either corn oil or $200 \mathrm{mg}$ P4 to Day 39 and hysterectomized on Day 40 indicated more Arg in uterine flushings in response to $\mathrm{P} 4(4,955 \pm 2,534$ vs. $726 \pm 133), \operatorname{Arg}(207,112 \pm 160,979 v s$. $7,409 \pm 2,877)$ and Leu $(248,255 \pm 178,599$ vs. $13,983 \pm 5,225)$, but due to high variability and small sample size these differences were not statistically significant. We also determined that uterine flushings from gilts on Day 90 of pseudopregnancy contained significant amounts (nmol) of Gluc $(14,007 \pm 3,946)$, Arg $(9,051 \pm 1,959)$, Gln $(4,949 \pm 1,449)$ and Leu $(2,455 \pm 771)$.

A series of experiments were recently performed to examine glucose, amino acids, the facilitated glucose transporters $S L C 2 A 1-4$, the sodium dependent glucose transporters SLC5A1 and SLC5A11, and the amino acid transporters SLC7A1-3, SLC7A8, SLC6A9 and SLC38A1 [G.A. Johnson and F.W. Bazer, unpublished results]. As reported above, Glucose, Arg, Leu and Gln increased in uterine flushings with day of the cycle and pregnancy, but only Arg increased to a greater extent in pregnant than cyclic gilts on Days 12 and 15. SLC2A3, SLC5A11, SLC7A1 and SLC7A2 mRNAs were not detectable by in situ hybridization in conceptus or uterine tissues. Expression patterns for $S L C 2 A 1$ and $S L C 2 A 4$ were similar, but $S L C 2 A 4$ was more abundant in conceptuses and in uterine LE from Days 15 through 80. SLC2A2 mRNA was abundant in conceptuses from Days 12 to 40, decreased to Day 50 and then increased and was maintained specifically in placental areolae to Day 85. SLC5A1 mRNA was only expressed in uterine LE between Days 9 and 15 of pregnancy. SLC7A3, an Arg transporter, increased in the entire chorion between Days 25 and 30, and expression was maintained to Day 85. When cyclic gilts were treated with E2-benzoate to produce pseudopregnancy, the uterine flushings contained significant amounts (nmol; means \pm SEM, $\mathrm{n}=4)(14.01 \pm 3.95)$, Arg (9.05 \pm 1.96$)$, Gln (4.95 \pm 1.45$)$ and Leu (2.46 \pm 0.77$)$. SLC $2 A 1, S L C 2 A 4$ and SLC4A1 mRNAs were expressed in the LE of pseudopregnant gilts. When gilts were ovariectomized and injected daily with P4, values ( $\mu$ mol; means $\pm \mathrm{SEM}, \mathrm{n}=4$ ) were greater for P4-treated than control gilts, respectively, for glucose (4.96 \pm 2.53 vs. $0.73 \pm 0.13)$, Arg

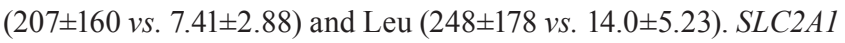
and SLC2A4 mRNAs were expressed in uterine LE of P4-treated gilts. Interestingly the small neutral amino acids, serine, glycine, threonine and alanine were all significantly increased in uterine flushings of P4-treated gilts. Further, the mRNAs of two transporters for these amino acids, SLC7A 8 and SLC38A1, were more abundant in endometria from pregnant, pseudopregnant and P4-treated gilts as determined by slot blot hybridization. Therefore results in pigs indicate: 1) high expression of $S L C 7 A 3$ in the chorion when Arg transport across the placenta is maximal; 2) SLC5A1 expression is induced in LE by estrogens, likely from conceptuses; and 3) long-term effects of P4 increase uterine secretion of small neutral amino acids. It is likely that the select nutrients that increase in the uterine lumen due to these changes in transporter expression influence proliferation, migration, attachment and gene expression necessary for conceptus development and survival in pigs.

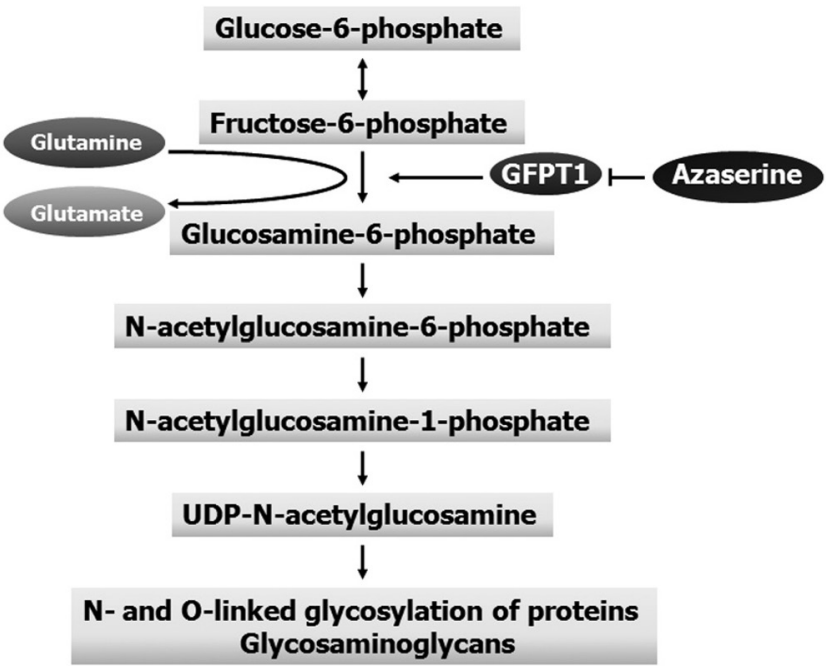

Fig. 3. Glucosamine-fructose-6-phosphate aminotransferase isomerizing 1 enzyme is encoded by the GFPT1 gene. Glutamine-fructose-6-phosphate transaminase 1 is the first and rate-limiting enzyme in the hexosamine pathway that controls the flux of glucose and fructose into the hexosamine pathway and catalyzes the formation of glucosamine 6-phosphate. Glucosamine6-phosphate is synthesized from fructose 6-phosphate and glutamine as the first step in the hexosamine biosynthesis pathway that results in synthesis of Uridine diphosphate $\mathrm{N}$-acetylglucosamine (UDP-GlcNAc) which is used for making glycosaminoglycans (e.g., chondroitin sulfates, dermatan sulfates, heparan sulfate and heparin, keratan sulfates, and hyaluronic acid) which are the polysaccharide subunits in proteoglycans, as well as glycolipids. UDP-GlcNAc is involved in intracellular signaling, nuclear pore formation and nuclear signalling and the glucose sensing mechanism of cells. For example, UDP-GlcNAc leads to the phosphorylation of tuberin and activation of MTOR [66].

We evaluated effects of Gluc and fructose (Fruc) to determine that both stimulate proliferation of $\mathrm{p} \operatorname{Tr} 2$ cells in vitro and that their effects are inhibited by azaserine, an inhibitor of Gln:Fruc6-phosphate transaminase 1 (GFPT1) that converts Fruc-6-PO4 to glucosamine-6-PO4 (J. Kim and F.W. Bazer, unpublished results). Further, both Gluc and Fruc metabolism via the hexosamine pathway (Fig. 3) leads to synthesis of hyaluronic acid in increasing amounts over a 5 day period of culture of $\mathrm{p} \operatorname{Tr} 2$ cells. There is also evidence that Gluc is converted to glucosamine-6-PO4 and then to UDP-N acetyl-glucosamine that phosphorylated TSC2 to remove inhibition from MTOR cell signaling that results in affects growth and development of trophoblast [64].

\section{Summary}

The review of effects of select nutrients, particularly Arg, but also Leu, Gln and Gluc indicate differential effects on activation of the MTORC1 nutrient sensing pathway for growth, development and differentiation, and implantation of ovine and porcine conceptuses during the peri-implantation period of pregnancy. Early exogenous P4 increases circulating concentrations of P4 in blood that, in turn, increases the abundance of select nutrients, particularly Arg 
and Gluc, in the uterine lumen, induces early down-regulation of PGR in uterine epithelia, accelerates blastocyst/conceptus growth and development, and advances onset of secretion of IFNT for pregnancy recognition signaling. The unique temporal and spatial expression of genes for nutrient transporters by uterine LE/sGE in direct contact with conceptus trophectoderm likely accounts for delivery of select nutrients critical to its development. The role of IRF2 in uterine LE/sGE to silence classical IFN stimulated genes allows the uterine LE/sGE to respond to P4 and IFNT by expressing a novel set of genes involved in nutrient transport, angiogenesis, cell proliferation and differentiation and tissue remodeling critical to expansion of the ovine blastocyst and then its transition to tubular and filamentous forms for implantation and placentation. Advances in transport of select nutrients, particularly Arg and Gluc, and secretion of various proteins by uterine LE/sGE and GE enrich uterine histotroph to support the advance conceptus development. Current research efforts are to determine the role of the MTORC2 pathway in conceptus elongation and mechanisms whereby P4, acting via progestamedins, acts additively or synergistically with IFNT to affect gene transcription. It is of interest that Gluc and Fruc can be metabolized by GFPT1 to glucosamine-6-PO4 and UDP-N-acetylglucosamine that act downstream of PI3K, but in FRAP1-dependent manner to stimulate proliferation of $\mathrm{pTr} 2$ cells. Results of studies with sheep, mice, pigs and cattle indicate the importance of the rate of increase in circulating concentrations of $\mathrm{P} 4$ post-ovulation on the uterine environment and conceptus development by enhancing the abundance of select nutrients in histotroph that advance conceptus development and increase survival of conceptuses through activation of the MTORC1 nutrient sensing cell signaling pathway.

\section{Acknowledgments}

The results presented in this manuscript were from research supported by USDA CSREES National Research Initiative Grant 2006-35203-17283, National Research Initiative Competitive Grant No. 2006-35203-17283 from the USDA National Institute of Food and Agriculture, and the World Class University (WCU) program (R31-10056) through the National Research Foundation of Korea funded by the Ministry of Education, Science, and Technology.

\section{References}

1. Nancarrow CD. Embryonic mortality in the ewe and doe. In: Zavy MT, Geisert RD (eds.), Embryonic Mortality in Domestic Species. CRC Press, 1994; 79-97.

2. Spencer TE, Johnson GA, Bazer FW, Burghardt RC. Implantation mechanisms: Insights from the sheep. Reproduction 2004; 128: 657-668. [Medline] [CrossRef]

3. Spencer TE, Johnson GA, Burghardt RC, Bazer FW. Progesterone and placental hormone actions on the uterus:insights from domestic animals. Biol Reprod 2004; 71: 2-10. [Medline] [CrossRef]

4. Bazer FW, Spencer TE, Johnson GA. Interferons and uterine receptivity. Semin Reprod Med 2009; 27: 90-102. [Medline] [CrossRef]

5. Bazer FW, Spencer TE, Johnson GA, Burghardt RC. Uterine receptivity to implantation of blastocysts in mammals. Frontiers in Bioscience 2011; 3: 745-767. [Medline] [CrossRef]

6. Bazer FW, Thatcher WW. Theory of maternal recognition of pregnancy in swine based on estrogen controlled endocrine versus exocrine secretion of prostaglan$\operatorname{din} \mathrm{F}_{2 \alpha}$ by the uterine endometrium. Prostaglandins 1977; 14: 397-400. [Medline]
[CrossRef]

7. Ziecik AJ, Waclawik A, Bogacki M. Conceptus signals for establishment and maintenance of pregnancy in pigs-lipid signaling system. Exp Clinical Endocrinol Diabetes 2008; 116: 443-449. [CrossRef]

8. Seo H, Kim M, Choi Y, Lee CK, Ka H. Analysis of lysophosphatidic acid (LPA) receptor and LPA-induced endometrial prostaglandin-endoperoxide synthase 2 expression in the porcine uterus. Endocrinology 2008; 149: 6166-6175. [Medline] [CrossRef]

9. Gray CA, Burghardt RC, Johnson GA, Bazer FW, Spencer TE. Evidence that absence of endometrial gland secretions in uterine gland knockout ewes compromises conceptus survival and elongation. Reproduction 2002; 124: 289-300. [Medline] [CrossRef]

10. Bartol FF, Wiley AA, Spencer TE, Vallet JL, Christenson RK. Early uterine development in pigs. J Reprod Fertil Suppl 1993; 48: 99-116. [Medline]

11. Gwatkin RB. Defined media and development of mammalian eggs in vitro. Ann NY Acad Sci 1966; 139: 79-90. [Medline] [CrossRef]

12. Martin PM, Sutherland AE. Exogenous amino acids regulate trophectoderm differentiation in the mouse blastocyst through an mTOR-dependent pathway. Dev Biol 2001; 240: 182-193. [Medline] [CrossRef]

13. Martin PM, Sutherland AE, Van Winkle LJ. Amino acid transport regulates blastocyst implantation. Biol Reprod 2003; 69: 1101-1108. [Medline] [CrossRef]

14. Nielsen FC, Ostergaard L, Nielsen J, Christiansen J. Growth-dependent translation of IGF-II mRNA by a rapamycin-sensitive pathway. Nature 1995; 377: 358-362. [Medline] [CrossRef]

15. Kimball SR, Shantz LM, Horetsky RL, Jefferson LS. Leucine regulates translation of specific mRNAs in L6 myoblasts through mTOR-mediated changes in availability of eIF4E and phosphorylation of ribosomal protein S6. J Biol Chem 1999; 274: 11647-11652. [Medline] [CrossRef]

16. Wu G, Bazer FW, Davis TA, Kim SW, Li P, Marc Rhoads J, Carey Satterfield M, Smith SB, Spencer TE, Yin Y. Arginine metabolism and nutrition in growth, health and disease. Amino Acids 2009; 37: 153-168. [Medline] [CrossRef]

17. Lefèvre PL, Palin MF, Chen G, Turecki G, Murphy BD. Polyamines are implicated in the emergence of the embryo from obligate diapause. Endocrinology 2011; 152: 1627-1639. [Medline] [CrossRef]

18. Lefèvre PL, Palin MF, Beaudry D, Dobias-Goff M, Desmarais JA, Llerena VE, Murphy BD. Uterine signaling at the emergence of the embryo from obligate diapause. Am J Physiol Endocrinol Metab 2011; 300: E800-E808. [Medline] [CrossRef]

19. Kim J, Burghardt RC, Wu G, Johnson GA, Spencer TE, Bazer FW. Select nutrients in the ovine uterine lumen. IX. Differential effects of arginine, leucine, glutamine, and glucose on interferon tau, ornithine decarboxylase, and nitric oxide synthase in the ovine conceptus. Biol Reprod 2011; 84: 1139-1147. [Medline] [CrossRef]

20. Hernández-Negrete I, Carretero-Ortega J, Rosenfeldt H, Hernandez-Garcia R, Calderon-Salinas JV, Reyes-Cruz G, Gutkind JS, Vazquez-Prado J. P-Rex1 links mammalian target of rapamycin signaling to Rac activation and cell migration. J Biol Chem 2007; 282: 23708-23715. [Medline] [CrossRef]

21. Yan L, Lamb RF. Signalling by amino acid nutrients. Biochem Soc Trans 2011; 39: 443-445. [Medline] [CrossRef]

22. Ka H, Jaeger LA, Johnson GA, Spencer TE, Bazer FW. Keratinocyte growth factor is up-regulated by estrogen in the porcine uterine endometrium and functions in trophectoderm cell proliferation and differentiation. Endocrinology 2001; 142: 2303-2310. [Medline] [CrossRef]

23. Eckert JJ, Fleming TP. Tight junction biogenesis during early development. Biochim Biophys Acta 2008; 1778: 717-728.

24. Hayashi K, Burghardt RC, Bazer FW, Spencer TE. WNTs in the ovine uterus: potential regulation of periimplantation ovine conceptus development. Endocrinology 2007; 148: 3496-3506. [Medline] [CrossRef]

25. Ohsugi M, Larue L, Schwarz H, Kemler R. Cell-junctional and cytoskeletal organization in mouse blastocysts lacking E-cadherin. Dev Biol 1997; 185: 261-271. [Medline] [CrossRef]

26. Biggers JD, Borland RM, Lechene CP. Ouabain-sensitive fluid accumulation and ion transport by rabbit blastocysts. J Physiol 1978; 280: 319-330. [Medline]

27. Benos DJ, Biggers JD, Balaban RS, Mills JW, Overström EW. Developmental aspects of sodium-dependent transport processes of preimplantation rabbit embryos. Soc Gen Physio Ser 1985; 39: 211-235. [Medline]

28. Geisert RD, Brookbank JW, Roberts RM, Bazer FW. Establishment of pregnancy in the pig: II. Cellular remodeling of the porcine blastocyst during elongation on day 12 of pregnancy. Biol Reprod 1982; 27: 941-955. [Medline] [CrossRef]

29. Geisert RD, Yelich JV. Regulation of conceptus development and attachment in pigs. J Reprod Fertil Suppl 1997; 52: 133-149. [Medline]

30. Albertini DF, Overstrom EW, Ebert KM. Changes in the organization of the actin cytoskeleton during preimplantation development of the pig embryo. Biol Reprod 
1987; 37: 441-451. [Medline] [CrossRef]

31. Mattson BA, Overstrom EW, Albertini DF. Transitions in trophectoderm cellular shape and cytoskeletal organization in the elongating pig blastocyst. Biol Reprod 1990; 42: 195-205. [Medline] [CrossRef]

32. Ito T. Role of histone modification in chromatin dynamics. J Biochem 2007; 141: 609-614. [Medline] [CrossRef]

33. Lopez-Bonet E, Vazquez-Martin A, Perez-Martinez MC, Oliveras-Ferraros C, Perez-Bueno F, Bernado L, Menendez JA. Serine 2481-autophosphorylation of mammalian target of rapamycin (mTOR) couples with chromosome condensation and segregation during mitosis: confocal microscopy characterization and immunohistochemical validation of PP-mTOR (Ser2481) as a novel high-contrast mitosis marker in breast cancer core biopsies. Int J Oncol 2010; 36: 107-115. [Medline]

34. Carson DD, Lagow E, Thathiah A, Al-Shami R, Farach-Carson MC, Vernon M, Yuan L, Fritz MA, Lessey B. Changes in gene expression during the early to mid-luteal (receptive phase) transition in human endometrium detected by high-density microarray screening. Mol Hum Reprod 2002; 8: 871-879. [Medline] [CrossRef]

35. Chen C, Spencer TE, Bazer FW. Fibroblast growth factor-10: A stromal mediator of epithelial function in the ovine uterus. Biol Reprod 2000; 63: 959-966. [Medline] [CrossRef]

36. Chen C, Spencer TE, Bazer FW. Expression of hepatocyte growth factor and its receptor c-met in the ovine uterus. Biol Reprod 2000; 62: 1844-1850. [Medline] [CrossRef]

37. Satterfield MC, Hayashi K, Song G, Black SG, Bazer FW, Spencer TE. Progesterone regulates FGF10, MET, IGFBP1, and IGFBP3 in the endometrium of the ovine uterus. Biol Reprod 2008; 79: 1226-1236. [Medline] [CrossRef]

38. Lassala A, Bazer FW, Cudd TA, Datta S, Keisler DH, Satterfield MC, Spencer TE, Wu G. Parenteral administration of L-arginine prevents fetal growth restriction in undernourished ewes. J Nutr 2010; 140: 1242-1248. [Medline] [CrossRef]

39. Lassala A, Bazer FW, Cudd TA, Datta S, Keisler DH, Satterfield MC, Spencer TE, Wu G. Parenteral administration of L-arginine enhances fetal survival and growth in sheep carrying multiple fetuses. $J$ Nutr 2011; 141: 849-855. [Medline] [CrossRef]

40. Wullschleger S, Loewith R, Hall MN. TOR signaling in growth and metabolism. Cell 2006; 124: 471-484. [Medline] [CrossRef]

41. Kim DH, Sarbassov DD, Ali SM, King JE, Latek RR, Erdjument-Bromage H, Tempst P, Sabatini DM. mTOR interacts with raptor to form a nutrient-sensitive complex that signals to the cell growth machinery. Cell 2002; 110: 163-175. [Medline] [CrossRef]

42. Liu L, Chen L, Chung L, Huang S. Rapamycin inhibits F-actin reorganization and phosphorylation of focal adhesion proteins. Oncogene 2008; 27: 4998-5010. [Medline] [CrossRef]

43. Murakami M, Ichisaka T, Maeda M, Oshiro N, Hara K, Edenhofer F, Kiyama H, Yonezawa K, Yamanaka S. mTOR is essential for growth and proliferation in early mouse embryos and embryonic stem cells. Mol Cell Biol 2004; 24: 6710-6718. [Medline] [CrossRef]

44. Bazer FW, Wu G, Johnson GA, Kim J, Song G. Uterine histotroph and conceptus development: select nutrients and secreted phosphoprotein 1 affect MTOR cell signaling in ewes. Biol Reprod 2011; Aug 24. [Epub ahead of print].

45. Gao H, Wu G, Spencer TE, Johnson GA, Li X, Bazer FW. Select nutrients in the ovine uterine lumen. I. Amino acids, glucose, and ions in uterine lumenal flushings of cyclic and pregnant ewes. Biol Reprod 2009; 80: 86-93. [Medline] [CrossRef]

46. Gao H, Wu G, Spencer TE, Johnson GA, Bazer FW. Select nutrients in the ovine uterine lumen. ii. Glucose transporters in the uterus and peri-implantation conceptuses. Biol Reprod 2009; 80: 94-104. [Medline] [CrossRef]

47. Gao H, Wu G, Spencer TE, Johnson GA, Bazer FW. Select nutrients in the ovine uterine lumen. III. Cationic amino acid transporters in the ovine uterus and periimplantation conceptuses. Biol Reprod 2009; 80: 602-609. [Medline] [CrossRef]

48. Gao H, Wu G, Spencer TE, Johnson GA, Bazer FW. Select nutrients in the ovine uterine lumen. IV. Expression of neutral and acidic amino acid transporters in ovine uteri and peri-implantation conceptuses. Biol Reprod 2009; 80: 1196-1208. [Medline] [CrossRef]

49. Gao H, Wu G, Spencer TE, Johnson GA, Bazer FW. Select nutrients in the ovine uterine lumen. V. Nitric oxide synthase, GTP cyclohydrolase, and ornithine decar- boxylase in ovine uteri and peri-implantation conceptuses. Biol Reprod 2009; 81: 67-76. [Medline] [CrossRef]

50. Gao H, Wu G, Spencer TE, Johnson GA, Bazer FW. Select nutrients in the ovine uterine lumen. VI. Expression of FK506-binding protein 12-rapamycin complexassociated protein 1 (FRAP1) and regulators and effectors of mTORC1 and mTORC2 complexes in ovine uteri and conceptuses. Biol Reprod 2009; 81: 87-100. [Medline] [CrossRef]

51. Kim JY, Burghardt RC, Wu G, Johnson GA, Spencer TE, Bazer FW. Select nutrients in the ovine uterine lumen. VII. Effects of arginine, leucine, glutamine, and glucose on trophectoderm cell signaling, proliferation, and migration. Biol Reprod 2011; 84: 62-69. [Medline] [CrossRef]

52. Kim JY, Burghardt RC, Wu G, Johnson GA, Spencer TE, Bazer FW. Select nutrients in the ovine uterine lumen. VIII. Arginine stimulates proliferation of ovine trophectoderm cells through MTOR-RPS6K-RPS6 signaling cascade and synthesis of nitric oxide and polyamines. Biol Reprod 2011; 84: 70-78. [Medline] [CrossRef]

53. Satterfield MC, Bazer FW, Spencer TE. Progesterone regulation of preimplantation conceptus growth and galectin 15 (LGALS15) in the ovine uterus. Biol Reprod 2006; 75: 289-296. [Medline] [CrossRef]

54. Satterfield MC, Dunlap KA, Hayashi K, Burghardt RC, Spencer TE, Bazer FW. Tight and adherens junctions in the ovine uterus: Differential regulation by pregnancy and progesterone. Endocrinology 2007; 148: 3922-3931. [Medline] [CrossRef]

55. Satterfield MC, Gao H, Li X, Wu G, Johnson GA, Spencer TE, Bazer FW. Select nutrients and their associated transporters are increased in the ovine uterus following early progesterone administration. Biol Reprod 2010; 82: 224-231. [Medline] [CrossRef]

56. Gray CA, Abbey CA, Beremand PD, Choi Y, Farmer JL, Adelson DL, Thomas TL, Bazer FW, Spencer TE. Identification of endometrial genes regulated by early pregnancy, progesterone, and interferon tau in the ovine uterus. Biol Reprod 2006; 74: 383-394. [Medline] [CrossRef]

57. Song G, Spencer TE, Bazer FW. Cathepsins in the ovine uterus: regulation by pregnancy, progesterone and interferon tau. Endocrinology 2005; 146: 4825-4833. [Medline] [CrossRef]

58. Song G, Wagner GF, Bazer FW, Spencer TE. Stanniocalcin (STC) in the endometrial glands of the ovine uterus: regulation by progesterone and placental hormones Biol Reprod 2006; 74: 913-922. [Medline] [CrossRef]

59. Song G, Satterfield MC, Kim J, Bazer FW, Spencer TE. Gastrin-releasing peptide (GRP) in the ovine uterus: regulation by interferon tau and progesterone. Biol Reprod 2008; 79: 376-386. [Medline] [CrossRef]

60. Kwon H, Wu G, Bazer FW, Spencer TE. Developmental changes in polyamine levels and synthesis in the ovine conceptus. Biol Reprod 2003; 69: 1626-1634. [Medline] [CrossRef]

61. Johnson GA, Bazer FW, Burghardt RC, Spencer TE, Wu G, Bayless KJ. Conceptus-uterus interactions in pigs: endometrial gene expression in response to estrogen and interferons from conceptuses. Soc Reprod Fertil Suppl 2009; 66: 321-332. [Medline]

62. Ka H, Al-Ramadan S, Erikson DW, Johnson GA, Burghardt RC, Spencer TE, Jaeger LA, Bazer FW. Regulation of expression of fibroblast growth factor 7 in the pig uterus by progesterone and estradiol. Biol Reprod 2007; 77: 172-180. [Medline] [CrossRef]

63. Bazer FW, Thatcher WW, Matinat-Botte F, Terqui M, Lacroix MC, Bernard S, Revault M, Dubois DH. Composition of uterine flushings from large white and prolific Chinese Meishan gilts. Reprod Fertil Dev 1991; 3: 51-60. [Medline] [CrossRef]

64. Bailey DW, Dunlap KL, Erikson DW, Patel A, Bazer FW, Burghardt RC, Johnson GA. Effects of long-term progesterone exposure on porcine uterine gene expression: progesterone alone does not induce secreted phosphoprotein 1 (osteopontin) in glandular epithelium. Reproduction 2010; 140: 595-604. [Medline] [CrossRef]

65. Bailey DW, Dunlap KA, Frank JW, Erikson DW, White BG, Bazer FW, Burghardt RC, Johnson GA. Effects of long-term progesterone on developmental and functional aspects of porcine uterine epithelia: progesterone alone does not support glandular development of pregnancy. Reproduction 2010; 140: 583-594. [Medline] [CrossRef]

66. Wen HY, Abbasi S, Kellems RE, Xia Y. mTOR: A placental growth signaling sensor. Placenta 2005; 26 Suppl A: S63-69. 